\title{
Multidetector computed tomographic evaluation of maxillofacial trauma
}

\author{
Kaleem Ahmad', R. K. Rauniyar ${ }^{2}$, Mukesh Kumar Gupta ${ }^{3}$, Sajid Ansari ${ }^{4}$, Ashok Raj Pant ${ }^{5}$, Abhishek Kumar ${ }^{6}$, \\ Basmah Abdur Rashid ${ }^{7}$
}

${ }^{1}$ Associate Professor, ${ }^{2}$ Professor, ${ }^{3}$ Associate Professor, ${ }^{4}$ Assistant Professor, ${ }^{5}$ Senior Resident, ${ }^{6}$ Senior Resident, Department of Radiodiagnosis, B. P. Koirala Institute of Health Sciences, Dharan, Nepal, ${ }^{7} J u n i o r$ Resident, Department of Radiodiagnosis, Sri Siddhartha Medical College, Agalakote, Tumkur, Karnataka

\section{A B S T R A C T}

Introduction: Maxillofacial injuries are one of the most frequently encountered entities accounting for a large proportion of patients in emergency department. Present study was performed to assess the role of multidetector computed tomography (MDCT) in patients of maxillofacial trauma and to describe the spectrum of various patterns of injuries in maxillofacial region in this part of Nepal. Methods: The study was carried out on a prospective basis over a period of one year. All the patients referred for evaluation of maxillofacial trauma were included in the study. MDCT was done in patients of maxillofacial injury and the data was recorded and analyzed. Volumetric MDCT scan of the maxillofacial region was performed in axial plane with multiplanar reconstruction in coronal and sagittal planes were obtained wherever required. Results: Out of 60 patients of maxillofacial trauma 42 (70\%) were males and $18(30 \%)$ were females and age ranges from 12 to 70 years. The 11-30 years age group has the highest percentage (55\%) of maxillofacial trauma, followed by $31-40$ (20\%). The common cause of injuries in our study was road traffic accidents $(58.33 \%)$, fall from height $(20 \%)$, physical assault $(16.66 \%)$ and sport injuries $(5 \%)$. Out of 60 patients there was total of 115 fractures. The frequency and types of fracture was as follows: orbital floor fracture in $21(35 \%)$, maxillary sinus wall fracture in $18(30 \%)$, nasal bone fracture in $17(28.33 \%)$, jaw fracture in $15(25 \%)$, zygomatic bone fracture in $13(21.66 \%)$, orbital wall fracture in $11(18.33 \%)$, naso-ethmoidal fractures in $9(15 \%)$, frontal sinus fracture in $7(11.66 \%)$, Lefort fracture in $1(1.66 \%)$ and others $3(5 \%)$. The highest percentage of fracture was of orbital floor (35\%) followed by fracture of wall of maxillary sinus $(30 \%)$ and nasal bone fracture (28.33\%). Three cases had simultaneous injury of the globe and cervical spine; they underwent computed tomography/magnetic resonance imaging for the assessment of spine. Conclusion: Injuries to maxillofacial region is one of the most common emergency requiring accurate and early diagnosis for preventing unnecessary investigations and proper management. MDCT has high sensitivity and specificity and has high accuracy for detection of fracture.

Key words: Maxillofacial, Fractures, Computed tomography, Trauma
Access this article online Website:

http://nepjol.info/index.php/AJMS

\section{INTRODUCTION}

Various injuries are caused by violence, the head and neck regions are most commonly affected. The largest proportion of admissions to hospital is due to trauma to these regions. ${ }^{1}$ Injury to the facial region may lead to life threatening situations i.e., airway compromise and profuse blood loss. ${ }^{2}$ Due to soft tissue swelling, lacerations and pain, it is difficult to physically examine the patient with facial trauma., ${ }^{3,4}$ The growing frequency and magnitude of road traffic accidents, as well as the increase in episodes of urban violence, have made these traumas a form of social disease. ${ }^{5}$ Now-a-days injuries due to road traffic accidents and violence are the common reasons which has significantly led to the increase in the frequency of maxillofacial injuries. ${ }^{5-7}$ These maxillofacial injuries are often managed by surgical consultation. ${ }^{7}$ Due to tremendous 
evolution in technology and novel therapeutic strategies the outcome of the patients with trauma has reasonably improved. The main aim of imaging studies in the trauma settings are to define the exact number and exact location of facial fractures, with particular attention toward identifying injuries to functional portions of the face and those with cosmetic outcomes. By appreciating properly the patterns of fracture and the implications for clinical management, radiologists can better imply clinically relevant radiology reports and hence facilitating improved communication with referring clinicians. Multidetector computed tomography (MDCT) is the imaging modality of choice and is one of the most important imaging tools in evaluation of patients with maxillofacial trauma. It helps in detecting the exact site, number and extent of fractures, displacement of fragments and soft tissue injuries. ${ }^{5,6,8}$ The added advantage of MDCT is 3-D reconstruction and multiplanar reformation in coronal and sagittal planes which are extremely helpful in assessing the bony architecture in large comminuted, displaced and complex fractures involving multiple planes ${ }^{9}$ that helps the surgeons for appropriate planning and management. Role of MRI in maxillofacial trauma is to assess the soft tissue injuries, it has excellent soft tissue contrast; and also aids in assessing the patients with neurological deficits. However, it has insignificant role in the evaluation of cortical bone. The role of plain radiographs in assessing maxillofacial trauma have declined as it does not provides adequate information besides, it could be life threatening while positioning the patients in co-existing cervical injuries.

\section{MATERIALS AND METHODS}

The study was carried out on a prospective basis in the Department of Radiodiagnosis and Imaging, B P Koirala Institute of Health Sciences, over the period of two years. A total of 60 cases were included in this study based on clinical suspicion of maxillofacial injury. MDCT was performed in all the cases and the findings were recorded. MDCT with volumetric acquisition was done in axial planes from upper border of frontal sinus to chin on 16- slice CT scanner (ECLOS 16, HITACHI, Japan) using standard CT protocol. From axial images thin sections $(1.25 \mathrm{~mm})$ were made through inbuilt software followed by multiplanar reconstructions (MPR) in coronal and sagittal planes along with 3D reconstruction. Fractures were classified as: nasal fractures, nasoethmoidal fractures, fractures of the zygomatic-malar complex, orbital floor fractures, maxillary sinus wall fractures, frontal sinus fractures, jaw fractures, Le Fort fractures and other fractures. Few cases had simultaneous injury of the globe and cervical spine; they underwent computed tomography/magnetic resonance imaging for the assessment of globe and for spinal cord injury. Plain radiographs were obtained in few of the patients as initial examination. Patients with normal findings were excluded from the study.

\section{RESULTS}

Out of 60 patients of maxillofacial trauma $42(70 \%)$ were males and $18(30 \%)$ were females and age of the patients ranged from 12 to 70 years. Maximum number of cases (55\%) was in 11-30 years of age group followed by (20\%) 31-40 years of age. The type and frequency of fractures are shown in Table 1. The common cause of injuries in our study was road traffic accidents $(58.33 \%)$, fall from height $(20 \%)$, physical assault $(16.66 \%)$ and sport injuries (5\%) as shown in Table 2. There was all together 115 fractures in 60 patients. The frequency and types of fracture (Table 3) were as follows: orbital floor fracture in $21(35 \%)$, maxillary sinus wall fracture in $18(30 \%)$, nasal bone fracture in $17(28.33 \%)$, jaw (mandible and maxilla) fracture in 15 (25\%) (Figure 1a \& b, 2a), zygomatic-malar complex fracture in $13(21.66 \%)$, orbital wall fracture in 11 (18.33\%), naso-ethmoidal fractures in $9(15 \%)$ (Figure 1c), frontal sinus fracture

\begin{tabular}{lcccc}
\multicolumn{5}{l}{ Table 1: Distribution according to age and sex } \\
\hline Age in years & Male & Female & Total & Percentage (\%) \\
\hline$<20$ & 9 & 4 & 13 & 22.66 \\
$21-30$ & 15 & 5 & 20 & 33.33 \\
$31-40$ & 10 & 2 & 12 & 20 \\
$41-50$ & 6 & 1 & 7 & 11.66 \\
$51-60$ & 3 & 0 & 3 & 5 \\
$61-70$ & 4 & 1 & 5 & 8.33 \\
& 47 & 13 & 60 & 100 \\
\hline
\end{tabular}

\begin{tabular}{lcc}
\multicolumn{3}{l}{ Table 2: Frequency and types of fractures in } \\
patients with maxillo-facial trauma \\
\hline Type of fracture & $\begin{array}{c}\text { Number } \\
\text { (n) }\end{array}$ & $\begin{array}{c}\text { Percentage } \\
\text { (\%) }\end{array}$ \\
\hline Orbital floor fracture & 21 & 35 \\
Fracture of maxillary sinus wall & 18 & 30 \\
Nasal bone fractures & 17 & 28.33 \\
Mandibular fractures & 15 & 25 \\
Fracture of zygomatic malar complex & 13 & 21.66 \\
Orbital wall fractures & 11 & 18.33 \\
Naso-ethmoidal fractures & 9 & 15 \\
Frontal sinus fractures & 7 & 11.66 \\
Le fort fractures & 1 & 1.66 \\
Others & 3 & 5 \\
\hline
\end{tabular}

\begin{tabular}{lcc} 
Table 3: Showing mode of injury & \\
\hline Mode of injury & $\begin{array}{r}\text { Number of patients } \\
(\mathbf{n}=\mathbf{6 0})\end{array}$ & $\begin{array}{c}\text { Percentage } \\
\mathbf{( \% )}\end{array}$ \\
\hline Road traffic accidents & 35 & 58.33 \\
Fall from height & 12 & 20 \\
Physical assault & 10 & 16.66 \\
Sport injuries & 3 & 5 \\
\hline
\end{tabular}




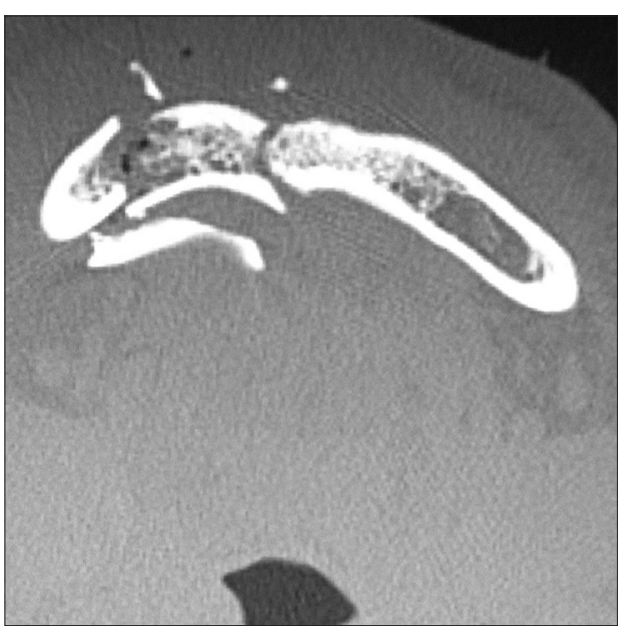

Figure 1a: Axial CT scan (bone window) showing comminuted fracture of the symphysis menti and mandibular body on right side

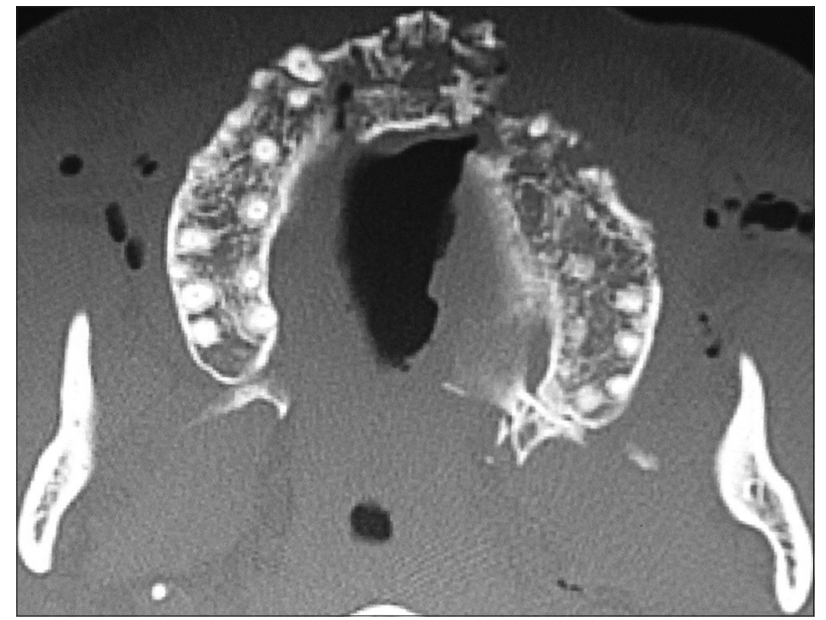

Figure 1b: Axial CT scan showing (bone window) showing comminuted fracture of the maxilla and left pterygoid plates

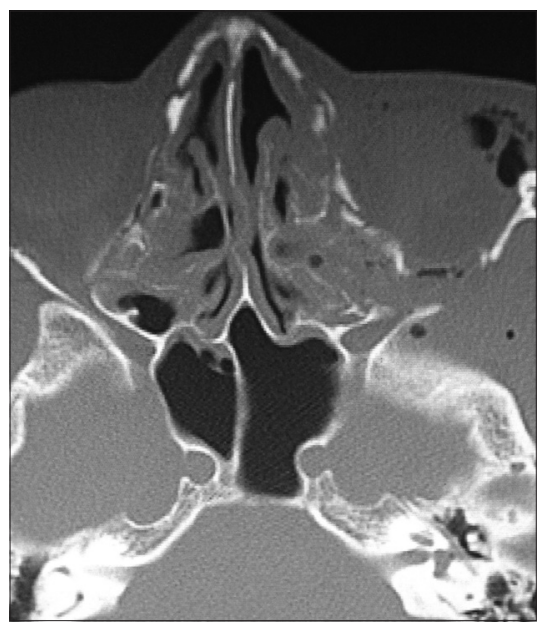

Figure 1c: Axial CT scan showing (bone window) showing comminuted fracture of nasal bones, bilateral lamina papyracea and lateral wall of the left orbit. Soft tissue density also seen in the ethmoid sinus suggesting hemosinus

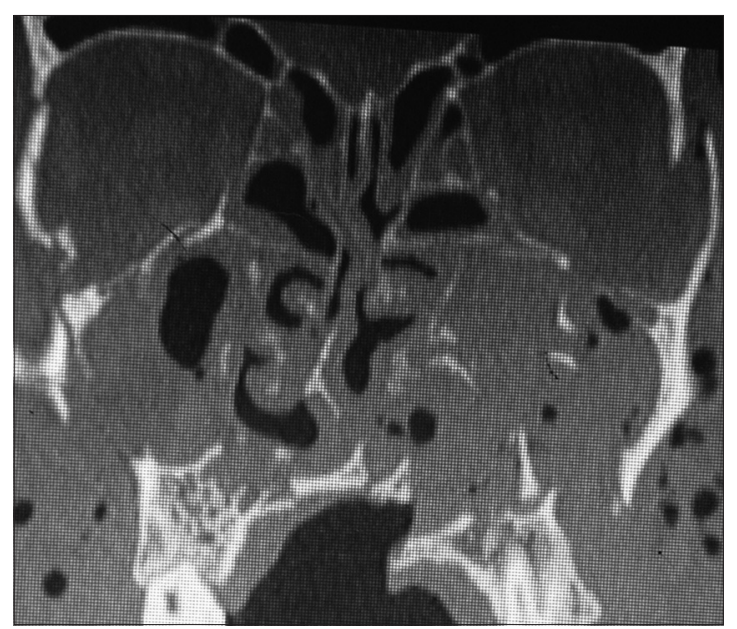

Figure 2a: Coronal CT scan (bone window) showing fracture of the hard palate, bilateral pterygoid plates and comminuted fracture of mandible

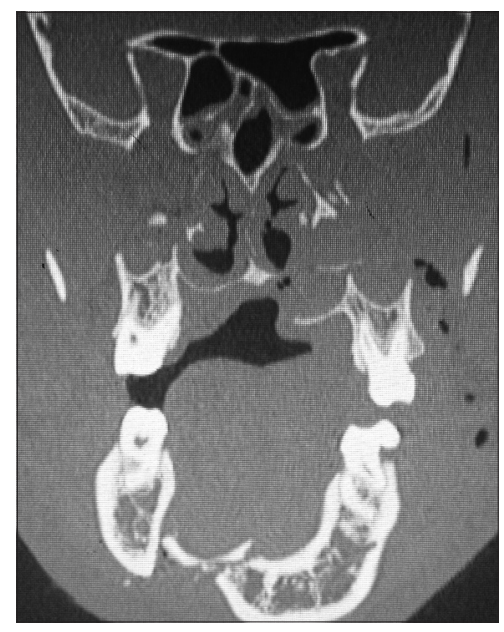

Figure 2b: Coronal CT Scan (bone window) showing comminuted fracture of hard palate, infero-lateral wall of bilateral orbit (blowout), medial and lateral wall of bilateral maxillary sinuses along with fluid collection in maxillary sinuses suggesting hemosinus

in $7(11.66 \%)$, Lefort fracture in $1(1.66 \%)$ and others $3(5 \%)$. The highest percentage of fracture was of orbital floor $(35 \%)$ followed by fracture of wall of maxillary sinus $(30 \%)$ and nasal bone fracture $(28.33 \%)$. Among the orbital floor fractures in 21 patients $7(33.33 \%)$ had blow out fracture (Figure $2 \mathrm{~b}$ ) of the orbit and $3(14.28 \%)$ patients had associated herniation of inferior rectus muscle and orbital fat into the maxillary sinus. Majority of the fractures of the wall of the maxillary sinus were having hemosinus. Five patients with fracture of nasal bone had collection of blood in the nasal cavity along with soft tissue swelling of the nostrils. Three patients had coexisting fracture of the nasal septum. Fractures of the zygomatic-malar complex in some of the cases were associated with soft tissue swelling of the malar region. Three cases had simultaneous injury of the globe and cervical spine; they underwent computed tomography/ magnetic resonance imaging for the assessment of spine. 


\section{DISCUSSION}

The facial skeleton is anatomically divided into five different regions: nasal, orbital, zygomatic, maxillary and mandibular. The nasal region is comprised of the nasal bones, lacrimal bones, and frontal process of the maxilla, nasal septum and ethmoid cells. Seven bones comprises the orbital region; the maxillary, zygomatic and frontal bones comprise the external orbital skeleton, while the internal orbit includes the lacrimal, palatine, ethmoid and sphenoid bones. The zygomatic process of the frontal bone, the zygomatic bone and the zygomatic process of the maxilla constitute the zygomatic region. The maxillary region includes the alveolar process and the bony components of the hard palate. Eventually, the mandibular region is made up of the mandible and the temporomandibular joint, and it is the only portion of the facial skeleton which is mobile..$^{10}$ The fractures in these regions are complex in nature because of their complex anatomy and are often associated with maxillary, zygomatic and/or nasal fractures, either in their internal or external region. In our study, the victims of violence were mostly males (70\%) and fracture of orbital floor was the most common fracture and was seen in $(35 \%)$ of patients which is consistent with the study done by Downing A et al. ${ }^{1}$ Salvolini $U$ reported that the most common causes of maxillofacial injuries are traffic accidents, injuries from fights, sport accidents or falls and the combination of road traffic accidents and injuries from fights account for $80 \%$ of maxillofacial fractures which is almost consistent with our study in which combination of road traffic accidents and physical violence accounted for $74.99 \%$ of maxillofacial fractures. The second most common fracture were walls of the maxillary sinus which constitutes $16 \%$ in the study done by Salvolini $\mathrm{U}$, which is in correlation with our study where second most common fracture was wall of the maxillary sinus. ${ }^{5}$ There are three classic fracture patterns of the maxilla, Le Fort I, II, and III. However, isolated fractures of the maxillary sinus are not common and generally consist of depressed fractures of the anterior wall of the maxillary sinus.,

The most common facial fractures are nasal fracture which accounts for approximately $50 \%$ of isolated fractures. ${ }^{5,8}$ The severity of the nasal fracture depends on the direction and amount of impact of trauma. Almost $66 \%$ of nasal fractures occurs due to lateral force and $13 \%$ from frontal impact. ${ }^{8}$ The indications for surgery to the patients of nasal trauma are septal fracture, septal dislocation, alteration of nasal bridge or severe soft tissue injury, whereas other fractures are managed conservatively. ${ }^{6,8,11}$ The frequency of naso-ethmoidal fractures is around $7 \%$. Direct blow to the lateral mid face results in zygomatic-malar complex fracture. Fracture of the three processes of the malar bone i.e., orbital, zygomatic and maxillary extends from the lateral wall of the orbit, to the postero-lateral wall of the maxillary sinus through the zygomatic arch, separating zygoma and maxilla., ${ }^{5,8}$ The indications for surgery are significant displacement of fragments, trismus, entrapment or involvement of the orbital apex. ${ }^{12}$ The general consensus is that open reduction and fixation is required for all the displaced fractures. ${ }^{13}$ The recent classification for these fractures ${ }^{14}$ are as follows: Type A- Fracture involving only one of the three processes of the malar bone; zygomatic arch, external orbital rim or infraorbital rim; Type B- Displaced trimalar fracture; Type C-Comminuted trimalar fracture.

Mandibular fractures comprises of the fracture of symphysis, alveolar process, body or horizontal ramus, angle, ascending ramus, coronoid process and mandibularcondyle. ${ }^{15,16}$ Pain, trismus, difficulty in chewing, malocclusion, swelling and fractures are the common presentations of the mandibular trauma. ${ }^{16}$ Any asymmetry in the occlusion is highly suggestive of mandibular fracture. ${ }^{17}$ The incidence of cervical spine injuries with facial trauma accounts for 1 to $10 \%$ according to various studies that could be asymptomatic at the time of initial presentation. Approximately $50 \%$ of patients with maxillofacial trauma have intracranial injuries. ${ }^{18,19}$ The fractures of the mandibular condyle are better appreciated in sagittal plane, while 3-D reconstructions (Figure 3) are extremely useful in planning surgical management. ${ }^{18-20}$ The sensitivity of multidetector computed tomography (MDCT) to detect mandibular fracture are $100 \%$ whereas orthopanoramic radiograph and conventional x-rays had only $86 \%$ sensitivity. ${ }^{16}$ Multidetector computed tomography (MDCT) is the investigation of choice and is the most appropriate imaging modality to evaluate patients of maxillofacial trauma. While evaluating orbital fractures, it is necessary to assess the optic nerve, the globe and the intraorbital soft tissues including the extraocular muscles. ${ }^{21,22}$

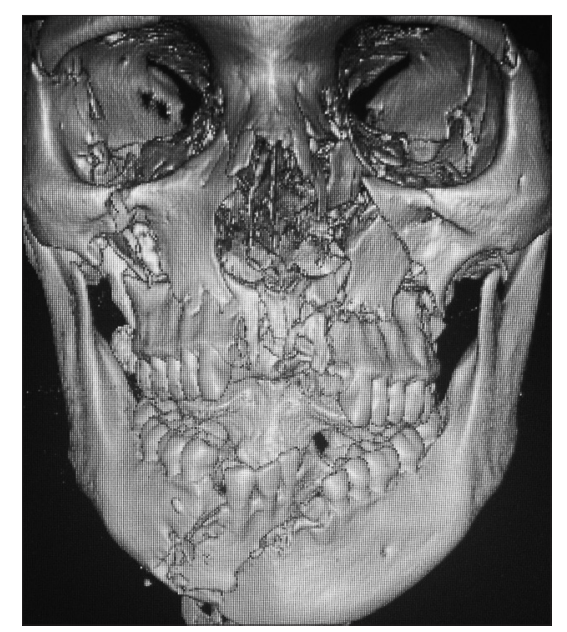

Figure 3: 3D Volume rendered image showing fracture of maxilla, mandible, inferior wall of right orbit and infero-medial wall of left orbit 


\section{CONCLUSION}

Maxillofacial injuries are commonly encountered emergencies which needs early diagnosis and management. Road traffic accidents and social violence are the common reasons which have led to increase in the frequency of maxillofacial injuries. The complex anatomies of the facial bones require multiplanar imaging techniques for a detailed evaluation. The main purpose of diagnostic imaging is to detect and localize the exact number, site of facial fractures and soft tissue injuries. MDCT offers excellent spatial resolution, which in turn enables exquisite multiplanar reformations, and 3-D reconstructions, allowing enhanced diagnostic accuracy and road map for surgical planning.

\section{REFERENCES}

1. Downing A, Cotterill S and Wilson R. The epidemiology of assault across the West Midlands. J Emerg Med 2003; 20: 434-437.

2. Perry M, Dancey A, Mireskandari K, Oakley P, Davies S and Cameron M. Emergency care in facial trauma - a maxillofacial and ophthalmic perspective. Injury 2005; 36: 875-896.

3. Goh S-H and Low B-Y. Radiologic screening for midfacial fractures: a single 30-degree occipitomental view is enough. J Trauma 2002; 52: 688-692.

5. Thai KN, Hummel RP, Kitzmiller WJ and Luchette FA. The role of computed tomographic scanning in the management of facial trauma. J Trauma 1997; 43: 214-218, 23.

6. Salvolini U. Traumatic injuries: imaging of facial injuries. Eur Radiol 2002; 12:1253-1261.

7. Mehta N, Butala P and Bernstein MP. The Imaging of Maxillofacial Trauma and its Pertinence to Surgical Intervention. Radiol Clin N Am 50; 2012:43-57.

8. Pathria $\mathrm{MN}$ and Blaser SI. Diagnostic imaging of craniofacial fractures. Radiol Clin North Am 1989; 27: 839-853.

9. Som PM and Brandwein MS. Facial fractures and postoperative findings. En: Som PM, Curtin HD (eds). Head and neck imaging. Mosby, St. Louis: 2002:374-438.

10. Saigal K, Winokur RS, Finden S, Taub D and Pribitkin EA. Use of three dimensional computerized tomography reconstruction in complex facial trauma. Arch Facial Plast Surg 2005; 21:214-219.

11. Avery LL, Susarla SM and Novelline RA. Multidetector and three-dimensional CT evaluation of the patient with maxillofacial injury. Radiol Clin N Am 2011; 49: 183-203.

12. Ondik MP, Lipinski L, Dezfoli $S$ and Fedok FG. The treatment of nasal fractures: a changing paradigm. Arch Facial Plast Surg 2009;11 (5):296-302.

13. Rohrich RJ, Hollier $\mathrm{LH}$ and Watumuli D. Optimizing the management of orbitozygomatic fractures. Clin Plast Surg 1992; 19:149-165.

14. Knight JS and North JF. The classification of malar fractures: an analysis of displacement as a guide to treatment. Br J Plast Surg 1961; 13:325-332.

15. Manson PN, Markowitz B, Mirvis S, Dunham $M$ and Yaremchuk M. Toward CT-based facial fracture treatment. Plast Reconstr Surg 1990; 85:202-212.

16. Schuknecht B and Graetz K. Radiologic assessment of maxillofacial, mandibular and skull base trauma. Eur Radiol 2005; 15:560-568.

17. Romeo A, Pinto A, Cappabianca S, Scaglione $M$ and Brunese L. Role of multidetector row computed tomograghy in the management of mandible traumatic lesions. Semin Ultrasound CT MRI 2009; 30:174-180.

18. Stacey DH, Doyle JF, Mount DL, Snyder MC and Gutowski KA. Management of mandible fractures. Plast Reconstr Surg 2006; 117:48-60e.

19. Mithani SK, St-Hilaire H, Brooke BS, Smith IM, BluebondLangner R and Rodriguez ED. Predictable patterns of intracranial and cervical spine injury in craniomaxillofacial trauma: analysis of 4786 patients. Plast Reconstr Surg 2009; 123:1293-1301.

20. Elahi MM, Brar MS, Ahmed N, Howley DB, Nishtar S and Mahoney JL. Cervical spine injury in association with craniomaxillofacial fractures. Plast Reconstr Surg 2008;121: 201-208.

21. Costa e Silva AP, Antunes JL and Cavalcanti MG. Interpretation of mandibular condyle fractures using $2 D$ and $3 D$ computed tomography. Braz Dent J 2003; 14:203-208.

22. Lee $\mathrm{H}$, Jilani $\mathrm{M}$, Frohman $\mathrm{L}$ and Baker $\mathrm{S}$. CT of orbital trauma. Emerg Radiol 2004; 10 (4):168-172.

23. Hopper RA, Salemy S and Sze RW. Diagnosis of midface fractures with CT: what the surgeon needs to know. Radiographics 2006; 26 (3):783-793.

\footnotetext{
Authors Contribution:

KA - Concept and design of the study, manuscript preparation, analysis and interpretation, critical revision of the manuscript, data collection and literature search; RKR - concept and design of the study, manuscript preparation, analysis and interpretation, critical revision of the manuscript, statistical analysis; MKG - manuscript preparation, literature search, critical revision of the manuscript, statistical analysis; SA - manuscript preparation, literature search, analysis and interpretation, data collection; ARP - analysis and interpretation, critical revision of the manuscript, literature search; AK - analysis and interpretation, literature search, critical revision of the manuscript, literature search; BAR - statistical analysis, literature search, statistical analysis, data collection
}

Source of Support: Nil, Conflict of Interest: None declared. 